Tohoku J. exp. Med., 1985, 145, 39-47

\title{
Pepsinogen Isozymes in Borrmann IV Type Gastric Garcinoma
}

\author{
Katsuhiro Nakamura and Hiroshi Sue \\ Department of Clinical Research, Sendai National \\ Hospital, Sendai 983
}

\begin{abstract}
Nakamura, K. and Sue, H. Pepsinogen Isozymes in Borrmann IV Type Gastric Carcinoma. Tohoku J. exp. Med., 1985, 145 (1), 39-47- Immunoperoxidase staining for human group I and group II pepsinogens (PG I, PG II) was performed on stomachs including surgically removed 42 Borrmann IV type gastric carcinomas (B-IV), 6 duodenal ulcers and 6 autopsy cases of traffic accident. Besides, 8 surgical cases of B-IV were examined by polyacrylamide gel electrophoresis (PAGE). All 8 cases examined by PAGE showed positive finding for at least one pepsinogen isozyme. In male, $19 / 19$ were positive while in female $21 / 23$ were positive for PG I and/or PG II by the immuno-peroxidase method.

scirrhus of the stomach ; pepsinogen isozymes ; electrophoresis ; PAP-method
\end{abstract}

Three groups of pepsinogen isozymes have been separated from human gastric mucosa by agar gel electrophoresis and they have been referred to as group I pepsinogen (PG I), group II pepsinogen (PG II) and slow moving protease (SMP) (Samloff 1969). Different antigenicities of PG I and PG II have also made possible to demonstrate their cellular localization by the immunofluorescent method. According to these results, the chief cells and mucous neck cells secrete PG I as well as PG II while the pyloric gland secretes PG II only (Samloff 1971; Samloff and Liebman 1973).

Meanwhile, signet ring cells which are commonly observed in human gastric carcinoma are morphologically similar to mucous neck cells and pyloric gland cells (Sasano et al. 1969). Therefore, production of pepsinogen isozymes by gastric carcinoma, especially by those consisting of signet ring cells seems highly probable.

Previously, one of the authors demonstrated by agar gel electrophoresis that some human gastric carcinoma produced PG II and SMP (Nakamura 1978). Hirsch-Marie et al. (1976) also demonstrated immunochemically cellular localization of pepsinogens in gastric cancers. In this paper, the authors selected the "scirrhus" of the stomach as the material in which the signet ring cell is a main constituent. And we demonstrated the existence of pepsinogen isozymes in

Received for publication, April 18, 1984.

Supported in part, by a grant-in-aid for Cancer Research from the Ministry of Health and Welfare, Japan. 
almost all "scirrhus" by polyacrylamide gel electrophoresis as well as by the immuno-peroxidase method.

\section{Materials AND Methods}

Materials used were 48 cases of surgically removed stomachs which included 42 Borrmann IV type gastric carcinomas (B-IV) and 6 duodenal ulcers. Besides, 6 stomachs from autopsy cases of traffic accident were also used as the material.

For polyacrylamide gel electrophoresis (PAGE), about $0.5 \mathrm{~g}$ of normal mucosa (6 duodenal ulcer cases and 2 autopsy cases) and about $1 \mathrm{~g}$ of cancer tissue (4 male and 4 female cases) which was completely separated from mucosa were used. Normal mucosae were sampled from the fundic, antral and pyloric regions. These materials were homogenized with 2 to 4 volumes of ice-cold $0.01 \mathrm{M}$ Tris-glycine buffer, $\mathrm{pH} 8.9$, in a glass homogenizer with a teflon pestle at 1,000 rpm for $5 \mathrm{~min}$. The homogenate was centrifuged at 3,000 rpm for $5 \mathrm{~min}$ and the sediment was discarded. Then, the supernatant obtained by centrifugation of the homogenate at $9,000 \times \mathrm{g}$ for $1 \mathrm{hr}$ was used as the enzyme extract. Electrophoresis of pepsinogen was achieved after the method of Furihata et al. (1972) with a minor modification. The solution of $7.5 \%$ polyacrylamide in $0.01 \mathrm{M}$ Tris-glycine buffer, $\mathrm{pH} 7.9$, was used to prepare gel plates. The $0.1 \mathrm{M}$ of the same buffer was also used for electrophoresis. After electrophoresis, the gel plates were immersed in $0.02 \mathrm{~N} \mathrm{HCl}$ solution containing $0.65 \%$ bovine hemoglobin $(\mathrm{pH} \doteqdot 1.8)$. Digestion of hemoglobin was allowed to proceed for $1 \mathrm{hr}$ at $37^{\circ} \mathrm{C}$. The gel plates were then fixed in $5 \%$ trichlor acetic acid, stained with $1 \%$ amidoblack $10-\mathrm{B}$ in 5 voulmes of ethyl alcohol, 5 volumes of distilled water and 1 volume of acetic acid for $15 \mathrm{~min}$ and differentiated in the same solvent for about $30 \mathrm{~min}$.

For immuno-peroxidase staining, tumor tissues were fixed in $10 \%$ formalin solution and embedded in paraffin. The PAP method (Burns 1975) and hematoxylin-eosin staining were applied to $4 \mu \mathrm{m}$-thick paraffin sections. As primary antiserum, rabbit anti-human group I pepsinogen and group II pepsinogen antibodies (kindly supplied by Dr. Miki, K., The Third Department of Internal Medicine, Faculty of Medicine, University of Tokyo, Tokyo) (Ichinose 1982) were used for a PAP indirect immuno-peroxidase method.

After PAGE of gastric mucosal extract of a duodenal ulcer case, immuno-blotting was achieved (Towbin et al. 1979). Proteases were transferred electrophoretically to a nitro cellulose membrane from the gel plate using Toyo-Model ETB-15. Then, immunoperoxidase staining was applied to the proteases on the nitro cellulose membrane with antibodies to PG I and PG II.

\section{RESUlts}

As for the results of PAGE, fundamentally no differences were observed between surgically removed duodenal ulcer cases and autopsy materials of traffic accidents. In Fig. 1, a PAGE pattern obtained from a duodenal ulcer case is shown. The authors used the nomenclature of gel electrophoretic patterns of gastric mucosal proteases basically after Samloff (1969): Group I pepsinogen (PG I) which consists of pgs 1 to 5 (in this paper, they were referred to as the bands 1 to 5), group II pepsinogen (PG II) which consists of pgs 6 to 7 (in this paper, the bands 6 to 7 ) and slow moving protease (SMP). However, in our results, minor differences were observed as follows: The band 1 was not observed, SMP sometimes appeared as three subbands and a new band was observed between the band 7 and SMP (tentatively, this was referred to as the band 8 ). The bands 2 to 7 , band 8 and SMP were all present in the fundic mucosa while the bands 2 to 


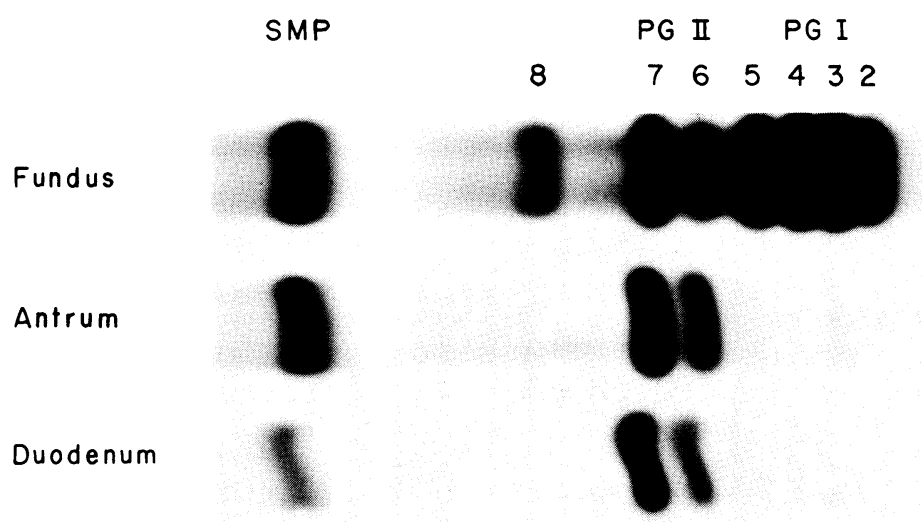

Fig. 1. PAGE of fundic, antral and duodenal mucosae from duodenal ulcer case. The photograph was printed directly from a gel plate.

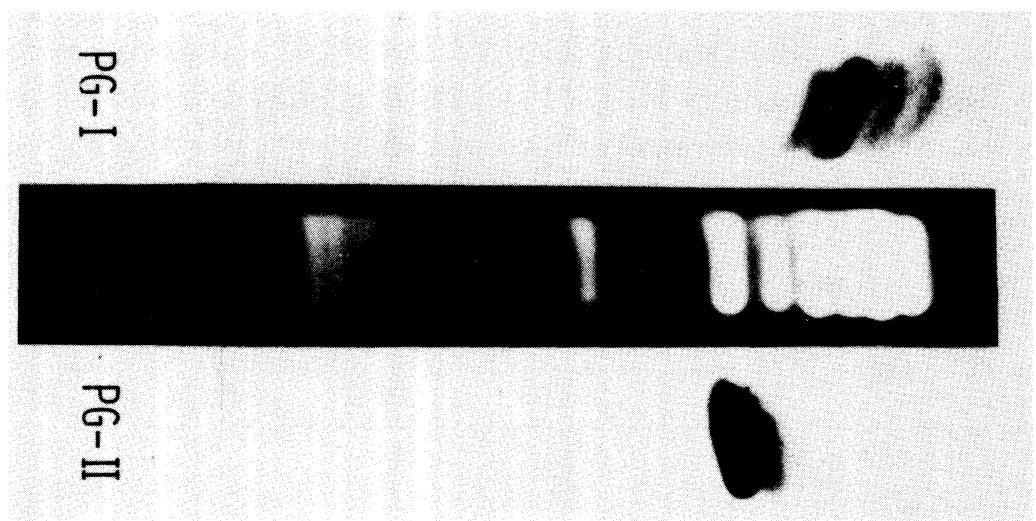

Fig. 2. Immuno-blotting of pepsinogen isozymes. Center of the figure is a PAGE of the fundic mucosa from a duodenal ulcer case. Upper and lower ones are pepsinogen isozymes which are transferred to the nitro cellulose membrane and stained with indirect immuno-peroxidase staining for GP I and PG II, respectively.

5 , band 8 and sometimes band 6 were not obvious in some antral mucosae. In the duodenal mucosa, the bands 6 to 7 and SMP was present. SMP observed in the antral and duodenal mucosa was weaker than that in the fundic mucosa and usually appeared as a single band.

Fig. 2 shows the results of immuno-blotting. The bands 2 to 5 (PG I) was stained with anti-PG I antibody and not with anti-PG II antibody while the bands 6 to 7 were stained only with anti-PG II antibody. The band 8 and SMP were not stained with either anti-PG I or -PG II antibodies.

A result of PAGE of carcinoma tissue is shown in Fig. 3 and the results are summarized in Tables 1 and 2 . As shown in Table 1, all male cases which were examined by PAGE were positive for pepsinogen isozymes. There was a characteristic female case which showed positive finding only for SMP. 


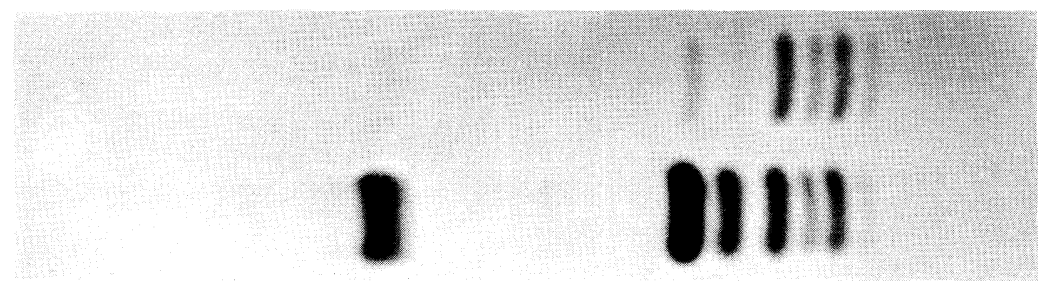

Fig. 3. PAGE of carcinoma tissue. The photograph was printed directly from a gel plate. Upper part is a result of PAGE of the "scirrhus". Lower one is that of a duodenal ulcer case. PG I, II and SMP are all positive in the carcinoma tissue.

As for PG I and PG II demonstrated by the PAP method, the gastric mucosa obtained from duodenal ulcer cases and autopsy cases showed the same cellular localization. PG I was demonstrated in chief cells and mucous neck cells while PG II was demonstrated in the pyloric gland and Brunner's gland as well as chief cells and mucous neck cells.

The degree of positive staining for PG I and PG II was graded as follows :

1) Degree of stainability for PG I and PG II of chief cells and mucous neck cells observed in the autopsy cases of traffic accidents was graded as "+".

2) In surgically removed gastric mucosae of the duodenal ulcer, chief cells

TABLE 1. Results of PAP and PAGE (male B-IV)

\begin{tabular}{|c|c|c|c|c|c|c|}
\hline \multirow{2}{*}{ Case } & \multirow{2}{*}{ Age } & \multicolumn{2}{|c|}{ PAP } & \multicolumn{3}{|c|}{ PAGE } \\
\hline & & PG I & PG II & PG I & PG II & SMR \\
\hline 1 & 28 & \pm & \pm & + & + & - \\
\hline 2 & 33 & H & H & & & \\
\hline 3 & 35 & + & + & & & \\
\hline 4 & 37 & H & H & & & \\
\hline 5 & 39 & + & H & & & \\
\hline 6 & 43 & $H$ & H & & & \\
\hline 7 & 44 & + & \pm & & & \\
\hline 8 & 50 & + & \pm & + & + & + \\
\hline 9 & 52 & H & + & + & + & + \\
\hline 10 & 53 & $H$ & H & + & + & + \\
\hline 11 & 53 & + & H & & & \\
\hline 12 & 56 & + & + & & & \\
\hline 13 & 60 & $H$ & $H$ & & & \\
\hline 14 & 60 & + & - & & & \\
\hline 15 & 62 & \pm & - & & & \\
\hline 16 & 62 & $H$ & H & & & \\
\hline 17 & 64 & \pm & + & & & \\
\hline 18 & 67 & $H$ & $H$ & & & \\
\hline 19 & 68 & H & + & & & \\
\hline
\end{tabular}


TABLE 2. Results of PAP and PAGE (female B-IV)

\begin{tabular}{|c|c|c|c|c|c|c|}
\hline \multirow{2}{*}{ Case } & \multirow{2}{*}{ Age } & \multicolumn{2}{|c|}{ PAP } & \multicolumn{3}{|c|}{ PAGE } \\
\hline & & $\mathrm{PG} \mathrm{I}$ & PG II & PG I & PG II & SMP \\
\hline 1 & 26 & - & - & & & \\
\hline 2 & 26 & H & H & & & \\
\hline$* 3$ & 27 & - & - & - & - & + \\
\hline 4 & 36 & H & + & & & \\
\hline 5 & 36 & + & H & & & \\
\hline 6 & 38 & H & + & & & \\
\hline 7 & 38 & + & H & & & \\
\hline 8 & 39 & + & \pm & - & + & - \\
\hline 9 & 40 & H & H & + & + & - \\
\hline 10 & 40 & + & + & & & \\
\hline 11 & 40 & \pm & \pm & & & \\
\hline 12 & 41 & H & + & & & \\
\hline 13 & 43 & $H$ & H & & & \\
\hline 14 & 44 & \pm & - & & & \\
\hline 15 & 44 & H & H & & & \\
\hline 16 & 45 & \pm & \pm & & & \\
\hline 17 & 46 & + & \pm & & & \\
\hline 18 & 53 & \pm & + & - & - & + \\
\hline 19 & 57 & + & + & & & \\
\hline 20 & 60 & \pm & \pm & & & \\
\hline 21 & 62 & H & H & & & \\
\hline 22 & 64 & H & $\#$ & & & \\
\hline 23 & 65 & + & H & & & \\
\hline
\end{tabular}

and mucous neck cells showed always rather weak staining for PG I as well as for PG II. These were graded as “ \pm ”. In noncancerous epithelia, there were no remarkable differences in degree due to sex.

3) When carcinoma cells focally showed the same degree as 1) or they diffusely did the same degree as 2), they were graded as " + ".

4) When carcinoma cells focally showed the same degree as 2), they were graded as " $\pm "$.

5) When carcinoma cells diffusely showed the same or more stronger degree than 1), they were graded as "\#".

The results for cancer tissues observed by the PAP method are summarized in Tables 1 and 2. Histologically, all cases consisted at least partly of signet ring cells. Only one (case 15) out of 19 male cases showed faint reaction for both PG $\mathrm{I}$ and PG II by the PAP method. In Figs. 4 and 5, positive findings for PG I and PG II are shown. Female cases showed generally weaker stainability than that of male cases, and the number of female cases in which PG I predominant over PG 


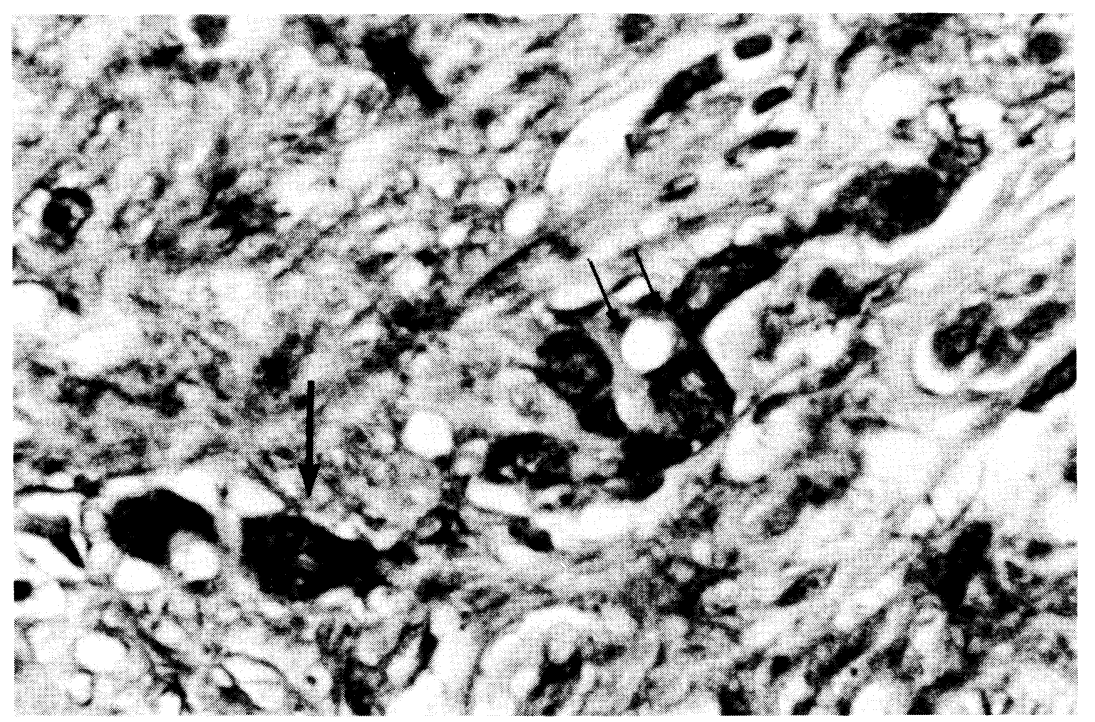

Fig. 4. Indirect immuno-peroxidase staining for PG I. Signet ring cells $(\rightarrow)$ and tubular adenocarcinoma $(\rightarrow)$ are all positive for $\mathrm{PG} \mathrm{I}$.

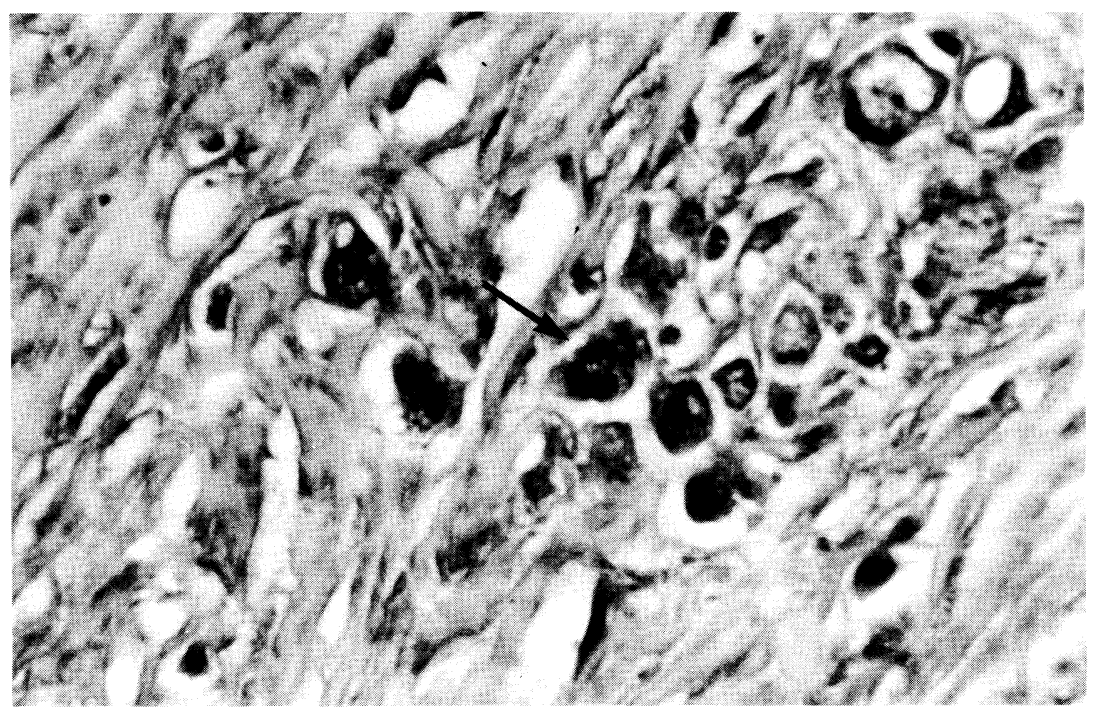

Fig. 5. Indirect immuno-peroxidase stainig for PG II. The cytoplasm of signet ring cell is stained granulated $(\rightarrow)$.

II was less than that of male. Moreover, there were some female cases negative for both PG I and PG II.

\section{Discussion}

Results of PAGE of gastric mucosal extracts were not different fundamen- 
tally from those of agar gel electrophoresis by Samloff (1969) but some minor differences were observed between them. According to Samloff (1971) and Samloff and Liebman (1973), PG I which consists of pgs 1 to 5 is only produced by chief cells and mucous neck cells in the fundic gland while PG II which consists of pgs 6 to 7 is widely found in the pyloric gland as well as in chief cells and mucous neck cells. In our results of PAGE, the first band of PG I (pg 1) was not distinct. Sometimes, the band 6 (pg 6) was not obvious in the samples obtained from the gastric antrum. The most slowly moving acid protease (SMP) was in our results, sometimes expressed by a single band but sometimes by triple bands, especially in the fundic mucosa. Moreover, between the band 7 and SMP the band 8 was sometimes faintly but almost constantly observed in fundic mucosa. Though the significance of these minor differences is not clear at present, the difference of gel plates or buffer solutions used for electrophoresis seems to give influence on the electrophoretic pattern of proteases. Highly acidic environment in duodenal ulcer would also yield some minor bands by autodigestion. Anyway, the immuno-blotting method showed that anti-PG I antibody used in this study reacted with the bands 2 to 5 (PG I) and anti-PG II antibody with the bands 6 to 7 (PG II).

Another problem for the results of PAGE is the occasional positive finding for $\mathrm{PG} I$ in the antral mucosa in which the pyloric glands are widely distributed (Whitecross et al. 1973). According to results of the PAP method, the pyloric gland is negative in PG I. Histologically, however, antral mucosa does not consist only of the pyloric gland. The sporadic fundic glands are usually observed in the antral mucosa even though they are small in number. Therefore, it seems probable that occasional positive finding of PAGE for PG I in antral mucosa is due to the coexistence of fundic gland.

In the B-IV cases of man, both PG I and PG II were markedly positive with a few exceptions, while in the cases of woman, PG II seemed as a main pepsinogen isozyme produced by the carcinoma. There were two cases which revealed electrophoretically positive finding only for SMP. One of these only SMPpositive cases which was marked by an asterisk in Table 2 was observed morphologically to be composed of signet ring cells of the surface epithelial type. In addition, some of the B-IV cases which were negative to both PG I and PG II showed the same morphological characteristics as above mentioned case. Details of these morphological findings of signet ring cell carcinoma will be described elsewhere. Though the authors have at present no antibody for SMP, we believe that the cases of signet ring cell carcinoma producing SMP are not so few in number. Thus, almont all cases of B-IV type gastric carcinoma were considered to produce pepsinogen isozymes.

Explanation for the difference of pepsinogen isozyme production by carcinoma in different sexes is not clear. Under a physiological condition, gastric mucosa of man provides with well developed fundic glands while pyloric glands 
occupy rather a wide area in the gastric mucosa of woman. Corresponding to these physiological conditions, it could be said that as for pepsinogen isozymes produced by B-IV type gastric carcinoma, the fundic gland type is prevailed in man while the pyloric gland type is common in woman. Sometimes, there were discrepancies between the results of PAGE and PAP-method. These may mostly arise from the difference in the sites of sampling.

One characteristic feature of B-IV type gastric carcinoma is the presence of signet ring cells. As for morphogenesis of the signet ring cell, is it difficult to suppose that pepsinogen isozymes which are produced by carcinoma tissue itself or by gastric mucosa around carcinoma would loosen or separate the intercellular connection of carinoma cells to form isolated signet ring cells? It is well known that we have used trypsin in order to isolate the cultured cells. If the carcinoma tissue localized in the mucosa or even if it infiltrates into a deeper layer accompanying with ulcer, the acidic environment would occur around the carcinoma tissue. Under these circumstances, activation of pepsinogen would easily occur.

Another important feature of the "scirrhus" is the marked fibrosis. Proteolytic activity of the enzyme would also soften the tissue around carcinoma and the following inflammatory change would cause marked fibrosis. As for fibrosis of "scirrhus", however, there have been some investigations that signet ring cells produce collagen and its precurser (Sakakibara et al. 1982). Anyway, morphogenesis of "scirrhus" would be attributed largely to the production of pepsinogen isozymes by carcinoma cells. And the authors suggested the cause of extremely random phenotypic expressions of signet ring cell carcinoma, for instance production of many kinds of polypeptide hormones (Tahara et al. 1982), pepsinogen isozymes and interstitial as well as epithelial collagen (Sakakibara et al. 1982), would be a loss of contact between cell membranes of carcinoma cells. Toroll et al. (1970) suggested that endogenous protease may play a role in the mechanisms of carcinogenesis, especially in promoting the process. The authors also consider that the significance of pepsinogen isozymes for the promotion as well as for the initiation of gastric carcinoma is very important.

\section{Acknowledgments}

We sincerely thank Mr. Shigeki Endo and Mr. Yasuo Ito for their technical assistance and Miss Miho Kato for her secretary assistance.

\section{References}

1) Burns, J. (1975) Background staining and sensitivity of the unlabelled antibodyenzyme (PAP) method. Comparison with the peroxidase labelled antibody sandwitch method using formalin fixed paraffin embedded materials. Histochem., 43, 291294.

2) Furihata, C., Kawachi, T. \& Sugimura, T. (1972) Premature induction of pepsinogen in developing rat gastric mucosa by hormones. Biochem. biophys. Res. Commun., 47, 705-711. 
3) Hirsch-Marie, H., Loisillier, P., Touboul, J.P. \& Burtin, P. (1976) Immunochemical study and cellular localization of human pepsinogens during ontogenesis and in gastric cancers. Lab. Invest., 34, 623-632.

4) Ichinose, M., Miki, K., Furihata, C., Kageyama, T., Miwa, H., Oka, H., Oda, T., Matsushima, T. \& Takahashi, K. (1982) Radioimmunoassay of group II pepsinogen in human serum. Clin. chem. Acta, 122, 61-69.

5) Nakamura, K. (1978) Cytological examination for morphogenesis of "scirrhus" of the stomach. J. Jap. Soc. Cancer Ther., 13, 748-749. (in Japanese)

6) Sakakibara, K., Suzuki, T., Motoyama, T., Watanabe, H. \& Nagai, Y. (1982) Biosynthesis of an interstitial type of collagen by cloned human gastric carcinoma cells. Cancer Res., 42, 2019-2027.

7) Samloff, I.M. (1969) Slow moving protease and the seven pepsinogens. Electrophoretic demonstration of the existence of eight proteolytic fractions in human gastric mucosa. Gastroenterology, 57, 659-669.

8) Samloff, I.M. (1971) Cellular localization of group I pepsinogens in human gastric mucosa by immunofluorescence. Gastroenterology, 61, 185-188.

9) Samloff, I.M. \& Liebman, W.M. (1973) Cellular localization of the group II pepsinogens in human stomach and duodenum by immunofluorescens. Gastroenterology, 65, $36-42$.

10) Sasano, N., Nakamura, K., Arai, M. \& Akazaki, K. (1969) Ultrastructural cell patterns in human gastric carcinoma compared with non-neoplastic gastric mucosa histogenetic analysis of carcinoma by mucin histochemistry. J. nat. Cancer. Inst., 43, 783-802.

11) Tahara, E., Ito, H., Nakagami, K., Shimamoto, F., Yamamoto, M. \& Sumi, K. (1982) Scirrhus argyrophil cell carcinoma of the stomach with multiple production of polypeptide hormones, amine, CEA, lysozyme, and HCG. Cancer, 49, 1904-1915.

12) Toroll, W., Klassen, A. \& Janoff, A. (1970) Tumorigenesis in mouse skin : Inhibition by synthetic inhibitors of proteases. Science, 169, 1211-1213.

13) Towbin, H., Stachelin, T. \& Gordon, J. (1979) Electrophoretic transfer of proteins from polyacrylamide gels to nitrocellulose sheets: Procedure and some applications. Proc. nat. Acad. Sci. USA, 76, 4350-4354.

14) Whitecross, D.P., Armstrong, C., Clarke, A.D. \& Piker, D.W. (1973) The pepsinogens of human gastric mucosa. Gut, 14, 850-855. 